\title{
Closing escape routes: inhibition of IL-8 signaling enhances the anti-tumor efficacy of PI3K inhibitors
}

Ashish Juvekar and Gerburg M Wulf*

\begin{abstract}
The phosphoinositide 3-kinase (PI3K) pathway serves as a relay where signals that emanate from the cell membrane are received and converted into intracellular signals that promote proliferation and survival. Inhibitors of PI3K hold promise for the treatment of breast cancer because activation of this pathway is highly prevalent. However, as is increasingly observed with inhibitors of cell signaling, there appear to be mechanisms of primary and secondary resistance. Britschgi and colleagues report that compensatory activation of the IL-8 signaling axis is a mechanism of primary resistance to PI3K inhibitors in some triplenegative breast cancers. In a set of experiments that carefully emulate the clinical scenario in a mouse model, they show that simultaneous inhibition of Janus kinase 2 enhances the efficacy of PI3K/mammalian target of rapamycin inhibition. Their paper lends further support to the concept that successful design of treatments with signal transduction inhibitors must anticipate potential escape routes - and include agents to simultaneously block them.
\end{abstract}

Metastatic triple-negative breast cancer (TNBC) remains an unsolved clinical problem. Patients are typically treated with cytotoxic chemotherapy that severely impedes their quality of life, response rates decline with each subsequent treatment regimen, and even when remission is achieved it is temporary and tumor progression occurs within a few months. The promise of targeted treatments is that, because of their specificity for the tumor cell's signaling machinery, they could potentially suppress tumor growth for a prolonged period and at lesser cost to quality of life. Two key challenges in the design of such studies are finding the right target and anticipating and counteracting resistance mechanisms.

*Correspondence: gwulf@bidmc.harvard.edu

Division of Hematology/Oncology, Beth Israel Deaconess Medical Center, 330 Brookline Avenue, Boston, MA 02215, USA
There is a good rationale to target phosphoinositide 3-kinase (PI3K) in breast cancer, including TNBC: 30 to $40 \%$ of estrogen receptor-positive breast cancer, 20 to $30 \%$ of Her 2 -amplified breast cancer, and 7 to $20 \%$ of TNBC have activating mutations of PIK3CA (encoding the p110 $\alpha$ subunit of PI3K) [1-4]. While the frequency of activating mutations in PIK3CA is relatively low in TNBC, an increase in epidermal growth factor receptor expression $[5,6]$ and inactivation of the inhibitory phosphatases PTEN and INPP4B $[7,8]$ are frequent, and thus activation of the PI3K pathway is also highly prevalent in TNBC.

These findings have led to a number of preclinical and now ongoing clinical studies examining the efficacy of PI3K inhibitor monotherapy and, anticipating resistance to PI3K/mammalian target of rapamycin (mTOR) monotherapy, of combination therapies that include Parp inhibitors [9,10] or MEK inhibitors [11]. In a set of elegant experiments that tries to recapitulate clinical scenarios closely in vitro and in a mouse model, Britschgi and colleagues examined the biological basis for resistance to PI3K/mTOR inhibition in TNBC [12].

Britschgi and colleagues show that inhibition of PI3K not only rewires intracellular signaling but also leads cancer cells to recruit alternate extracellular signaling mechanisms to circumvent PI3K (Figure 1). This inhibition occurs in a two-step process: within hours of exposure to the dual PI3K/mTOR inhibitor NVP-BEZ 235 , TNBC cells responded with upregulation of insulinreceptor signaling and with its downstream effector IRS1 directly activating Janus kinase 2 (JAK2) and its substrate, the transcription factor signal transducer and activator of transcription 5 (STAT5). Presumably through changing the transcriptional profile of the cancer cells, STAT5 then causes a more sustained upregulation of the IL- 8 signaling axis, including secretion of IL-8 and upregulation of its receptor CXCR1 that then takes over to maintain JAK2/STAT5 signaling (Figure 1). The net effect is that cancer cells which typically rely on receptor tyrosine kinases/PI3K signaling now shift to G-protein coupled receptors, in this case IL-8/CXCR1, to activate JAK2/STAT5 and to keep their mitotic machinery going. The biological significance of this stepwise transition 


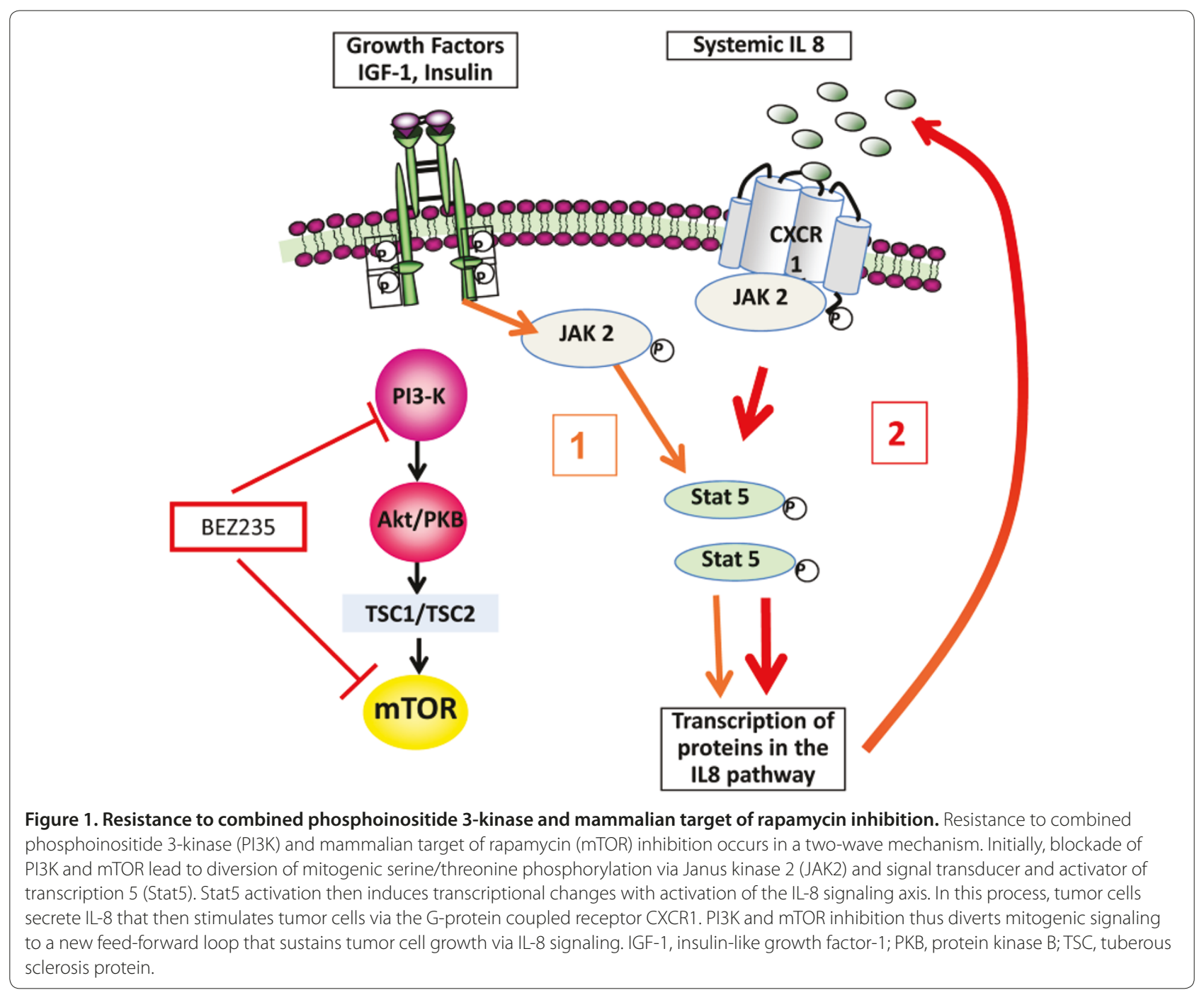

from receptor tyrosine kinases/PI3K to G-protein coupled receptor/JAK2 mitogenic signaling is confirmed by the findings that concomitant blockade of PI3K/mTOR and IL-8 signaling could effectively decrease tumor growth and metastasis and improve disease-free and overall survival in mice.

Britschgi and colleagues' findings illustrate the plasticity of the signaling mechanisms that drive cancer cells: PI3K/ mTOR inhibition is acutely compensated for by the recruitment of IRS1/JAK2/STAT5 phosphorylation and eventually by a change of the transcriptional program in a way that leads to independence from PI3K signaling. They show a pattern of resistance development where cancer cells immediately adapt with a change in phosphorylation routes, followed by transcriptional reprogramming. For the practical purposes of cancer treatment the question really is just how many escape routes there are for cancer cells to evade monotherapy with a targeted agent, and specifically PI3K inhibition. Notably, while disease-free and overall survival was increased, none of the tumors in Britschgi and colleagues' model were cured by the PI3K/JAK2 inhibitor combination. This failure to cure disease means that tumor cells found a third way around PI3K inhibition, and it is intriguing to speculate that this third wave of resistance may be due to the evolution of genetically resistant clones that, for example, harbor a myc amplification [13].

Will efforts to treat breast cancer with combinations of signal transduction inhibitors be akin to the boy who is trying to hold the flood with his fingers in the dyke? The observed order of events with immediate adaptation of signaling pathways over transcriptional reprogramming and eventually presumed outgrowth of genetically resistant clones suggests that there may be a finite number of escape pathways, and inhibitors to target them may already be available. In addition, this novel approach might target specific tumor cell populations that are not typically eradicated by chemotherapy. The fact that 
combined JAK2 plus PI3K/mTOR inhibition greatly decreased circulating tumor cells, and specifically metastasis formation, suggests that this approach could potentially enhance the efficacy of cytotoxic chemotherapy.

A number of findings in Britschgi and colleagues' work raise immediate clinically important questions. Only some TNBC cell lines responded to PI3K inhibition with an increase in JAK2/phosphorylated-STAT5 signaling is there a common genetic denominator that dictates this response? Could measurement of blood IL-8 levels identify patients whose tumors might be de novo resistant to PI3K inhibition? Would concomitant blockade of IL-8 receptors, important for neutrophil function, increase susceptibility to bacterial infections?

Rashes and non-infectious pneumonitis are known class effects that occur in patients treated with mTOR inhibitors [14], and may also occur with PI3K inhibitors. Given the significance of IL-8 levels as a biomarker for pneumonitis, it is interesting to speculate that compensatory IL-8 production might actually be the mechanism for this thus far unexplained toxicity, and, if so, concomitant blockade of IL-8 signaling and PI3K might actually reduce pulmonary toxicity. Lastly, there is no reason to assume that upregulation of IL-8 signaling upon PI3K inhibition is specific to breast cancer, and upregulation of the IL-8 signaling axis should be considered a potential resistance mechanism in all cancers where PI3K inhibition is currently being studied.

\section{Abbreviations}

JAK2, Janus kinase 2; IL, interleukin; mTOR, mammalian target of rapamycin; PI3K, phosphoinositide 3-kinase; STAT5, signal transducer and activator of transcription 5; TNBC, triple-negative breast cancer.

\section{Competing interests}

The authors declare that they have no competing interests.

Published: 8 April 2013

\section{References}

1. Marty B, Maire V, Gravier E, Rigaill G, Vincent-Salomon A, Kappler M, Lebigot I, Djelti F, Tourdes A, Gestraud P, Hupé P, Barillot E, Cruzalegui F, Tucker GC, Stern $\mathrm{MH}$, Thiery JP, Hickman JA, Dubois T: Frequent PTEN genomic alterations and activated phosphatidylinositol 3-kinase pathway in basal-like breast cancer cells. Breast Cancer Res 2008, 10:R101.

2. Esteva FJ, Guo H, Zhang S, Santa-Maria C, Stone S, Lanchbury JS, Sahin AA, Hortobagyi GN, Yu D: PTEN, PIK3CA, p-AKT, and p-p70S6K status: association with trastuzumab response and survival in patients with HER2-positive metastatic breast cancer. Am J Pathol 2010, 177:1647-1656.

3. Brachmann SM, Hofmann I, Schnell C, Fritsch C, Wee S, Lane H, Wang S, Garcia-Echeverria C, Maira SM: Specific apoptosis induction by the dual $\mathrm{PI3K} / \mathrm{mT}$ Tor inhibitor NVP-BEZ235 in HER2 amplified and PIK3CA mutant breast cancer cells. Proc Natl Acad Sci U S A 2009, 106:22299-22304.
4. Serra V, Markman B, Scaltriti M, Eichhorn PJ, Valero V, Guzman M, Botero ML, Llonch E, Atzori F, Di Cosimo S, Maira M, Garcia-Echeverria C, Parra JL, Arribas J, Baselga J: NVP-BEZ235, a dual PI3K/mTOR inhibitor, prevents PI3K signaling and inhibits the growth of cancer cells with activating PI3K mutations. Cancer Res 2008, 68:8022-8030.

5. Burga LN, Hu H, Juvekar A, Tung NM, Troyan SL, Hofstatter EW, Wulf GM: Loss of BRCA1 leads to an increase in epidermal growth factor receptor expression in mammary epithelial cells, and epidermal growth factor receptor inhibition prevents estrogen receptor-negative cancers in BRCA1-mutant mice. Breast Cancer Res 2011, 13:R30

6. Collins LC, Martyniak A, Kandel MJ, Stadler ZK, Masciari S, Miron A, Richardson AL, Schnitt SJ, Garber JE: Basal cytokeratin and epidermal growth factor receptor expression are not predictive of BRCA1 mutation status in women with triple-negative breast cancers. Am J Surg Pathol 2009, 33:1093-1097.

7. Gewinner C, Wang ZC, Richardson A, Teruya-Feldstein J, Etemadmoghadam D, Bowtell D, Barretina J, Lin WM, Rameh L, Salmena L, Pandolfi PP, Cantley LC Evidence that inositol polyphosphate 4-phosphatase type II is a tumor suppressor that inhibits PI3K signaling. Cancer Cell 2009, 16:115-125.

8. Fedele CG, Ooms LM, Ho M, Vieusseux J, O'Toole SA, Millar EK, Lopez-Knowles E, Sriratana A, Gurung R, Baglietto L, Giles GG, Bailey CG, Rasko JE, Shields BJ, Price JT, Majerus PW, Sutherland RL, Tiganis T, McLean CA, Mitchell CA: Inositol polyphosphate 4-phosphatase II regulates PI3K/Akt signaling and is lost in human basal-like breast cancers. Proc Natl Acad Sci U S A 2010, 107:22231-22236.

9. Juvekar A, Burga LN, Hu H, Lunsford EP, Ibrahim YH, Balmana J, Rajendran A, Papa A, Spencer K, Lyssiotis CA, Nardella C,Pandolfi PP, Baselga J, Scully R, Asara JM, Cantley LC, Wulf GM: Combining a PI3K inhibitor with a PARP inhibitor provides an effective therapy for a mouse model of BRCA1related breast cancer. Cancer Discov 2012, 2:1048-1063.

10. Ibrahim YH, García-García C, Serra V, He L, Torres-Lockhart K, Prat A, Anton P, Cozar P, Guzmán M, Grueso J, Rodríguez O, Calvo MT, Aura C, Díez O, Rubio IT, Pérez J, Rodón J, Cortés J, Ellisen LW, Scaltriti M, Baselga J: PI3K inhibition impairs BRCA1/2 expression and sensitizes BRCA-proficient triplenegative breast cancer to PARP inhibition. Cancer Discov 2012, 2:1036-1047.

11. Hoeflich KP, Merchant M, Orr C, Chan J, Den Otter D, Berry L, Kasman I, Koeppen H, Rice K, Yang NY, Engst S, Johnston S, Friedman LS, Belvin M: Intermittent administration of MEK inhibitor GDC-0973 plus $\mathrm{PI} 3 \mathrm{~K}$ inhibitor GDC-0941 triggers robust apoptosis and tumor growth inhibition. Cancer Res 2012, 72:210-219.

12. Britschgi A, Andraos R, Brinkhaus H, Klebba I, Romanet V, Muller U, Murakami M, Radimerski T, Bentires-Alj M: JAK2/STAT5 inhibition circumvents resistance to $\mathrm{PI} 3 \mathrm{~K} / \mathrm{mTOR}$ blockade: a rationale for cotargeting these pathways in metastatic breast cancer. Cancer Cell 2012, 22:796-811.

13. Liu P, Cheng H, Santiago S, Raeder M, Zhang F, Isabella A, Yang J, Semaan DJ, Chen C, Fox EA, Gray NS, Monahan J,Schlegel R, Beroukhim R, Mills GB, Zhao J): Oncogenic PIK3CA-driven mammary tumors frequently recur via PI3K pathway-dependent and PI3K pathway-independent mechanisms. Nat Med 2011, 17:1116-1120.

14. Ellard SL, Clemons M, Gelmon KA, Norris B, Kennecke H, Chia S, Pritchard K, Eisen A, Vandenberg T, Taylor M, Sauerbrei E,Mishaeli M, Huntsman D, Walsh W, Olivo M, Mclntosh L, Seymour L: Randomized phase II study comparing two schedules of everolimus in patients with recurrent/metastatic breast cancer: NCIC Clinical Trials Group IND.163. J Clin Oncol 2009, 27:4536-4541.

doi:10.1186/bcr3400

Cite this article as: Juvekar A, Wulf GM: Closing escape routes: inhibition of IL-8 signaling enhances the anti-tumor efficacy of PI3K inhibitors. Breast Cancer Research 2013, 15:308. 